\title{
Cathemeral activity patterns of the blue-eyed black lemur Eulemur macaco flavifrons in intact and degraded forest fragments
}

\author{
Nora Schwitzer ${ }^{1}$, Werner Kaumanns ${ }^{1}$, Peter C. Seitz ${ }^{2}$, Christoph Schwitzer ${ }^{3, *}$ \\ ${ }^{1}$ Working Group Primatology, Zoologischer Garten Köln, Riehler Strasse 173, 50735 Köln, Germany \\ ${ }^{2}$ Department of Biophysics, Technische Universität München, James Franck Strasse, 85748 Garching, Germany \\ ${ }^{3}$ Bristol Zoo Gardens, Clifton, Bristol BS8 3HA, UK
}

\begin{abstract}
This study describes the activity pattern of the blue-eyed black lemur Eulemur macaco flavifrons for the first time and investigates the parameters, such as season or habitat, that may influence the distribution of activity over the $24 \mathrm{~h}$ cycle. Four groups of E. m. flavifrons in 2 forest fragments with different degrees of degradation were followed for $24 \mathrm{~h} \mathrm{mo}^{-1}$ over a 7 mo period between July 2004 and July 2005. Blue-eyed black lemurs exhibited a bimodal activity pattern which peaked during the morning and evening twilight. The groups consistently showed activity bouts both during the day and at night, a behaviour that corresponds to Tattersall's (1987) definition of cathemerality. The proportion of illuminated lunar disc and the nocturnal illumination index were positively associated with the amount of nocturnal activity. Total activity, both diurnal and nocturnal, was significantly higher in the secondary than in the primary forest. In view of our results, the cathemeral behaviour of $E$. m. flavifrons may best be explained as flexible responses to a framework of varying environmental factors, each of which may enhance or inhibit activity within the lemurs' range of adaptability. This temporal behavioural plasticity may be an adaptation to an erratic and severe climate with frequent droughts and cyclones and unpredictable resource availability.
\end{abstract}

KEY WORDS: Eulemur macaco flavifrons $\cdot$ Cathemerality · Activity pattern · Nocturnal illumation index $\cdot$ Primary forest $\cdot$ Secondary forest

\section{INTRODUCTION}

Until about 30 years ago, primates were classified as either diurnal or nocturnal (Curtis et al. 2006). Beginning in the late 1970s, however, it was found that some lemur species of the genus Eulemur regularly exhibited both nocturnal and diurnal activity; i.e. they were active throughout the $24 \mathrm{~h}$ cycle (Curtis \& Rasmussen 2006, Tattersall 2006). This pattern was first described in the wild by Tattersall (1979) for Eulemur fulvus on the island of Mayotte, between northern Madagascar and northern Mozambique. Later the pattern was also also described for the congeneric species E. albifrons, E. albocollaris, E. collaris, E. coronatus, E. macaco macaco, E. mongoz, E. rubriventer, E. rufus and E. sanfordi (Wright 1999, Vasey 2000, Donati \& BorgogniniTarli 2006, Colquhoun 2006). Tattersall (1987) formally introduced the term 'cathemeral': 'the activity pattern of an organism can be regarded as cathemeral when it is about evenly distributed over the $24 \mathrm{~h}$ daily cycle, or when significant amounts of activity, particularly feeding and/or travelling, occur within both light and dark portions of the cycle' (p. 201). A cathemeral activity cycle has since also been reported in a number of other lemur genera, such as Hapalemur alaotrensis (Mutschler et al. 1998, Mutschler 2002) and Prolemur simus (Tan 2000, Grassi 2001), and in neotropical owl monkeys of the genus Aotus (Wright 1994, Kinzey 
1997, Fernandez-Duque 2003). Furthermore, cathemerality may occur in 2 howler monkey species, Alouatta pigra and A. palliata (Dahl \& Hemingway 1988, Wright 1994, Curtis \& Rasmussen 2002, Mutschler 2002, Fernandez-Duque 2003, Kirk 2006).

In the genus Eulemur, cathemerality may occur in 3 different modes (Curtis \& Rasmussen 2002): (1) varying seasonally, with nocturnal activity predominantly exhibited during one season and diurnal activity predominating during another (Tattersall 1979, 1987, Curtis \& Zaramody 1998, Rasmussen 1998a,b, Curtis et al. 1999, Curtis \& Rasmussen 2006, Tarnaud 2006); (2) shifting seasonally, from diurnal activity in the austral summer to $24 \mathrm{~h}$ activity in the austral winter (Rasmussen 1999, Donati et al. 1999, Donati \& Borgognini-Tarli 2006); (3) $24 \mathrm{~h}$ activity throughout the year with no link to photoperiod and seasonal variation of food resources (Colquhoun 1997, 1998). In the third group, the duration of nocturnal activity is positively correlated with lunar phase and nocturnal illumination index (Colquhoun 1997, Donati et al. 2001a,b, Donati \& Borgognini-Tarli 2006, Fernandez-Duque \& Erkert 2006).

According to Erkert \& Cramer (2006), Eulemur albifrons is endogenously regulated by a circadian timing system that seems to obey the same rules as for nocturnal mammals, where the daily light:dark cycle is the most efficient zeitgeber and synchronises this endogenous rhythm to the external $24 \mathrm{~h}$ day. In a 14 mo study on E. collaris in the Malagasy littoral forest, Donati \& Borgognini-Tarli (2006) demonstrated that dusk seems to act as the primary zeitgeber, coordinating the onset of the animals' evening activity throughout the entire year.

The blue-eyed black lemur Eulemur macaco flavifrons is a critically endangered lemur taxon (CR A1cd, B1+2bc; Ganzhorn et al. 2000) that exclusively inhabits the few remaining forest fragments on and east of the Sahamalaza peninsula (Sofia region, NW Madagascar). The subspecies was only rediscovered in 1983 after more than a century of uncertainty about its existence, and it is still one of the least-studied lemurs (Koenders et al. 1985, Meier et al. 1996). Whereas the other taxa of this genus (including the nominate subspecies E. m. macaco) have all been described as showing activity patterns that involve both day and night activity, E. m. flavifrons remains the only Eulemur whose activity pattern in the wild is still unknown. In captivity, blue-eyed black lemurs show cathemeral activity similar to that of other Eulemur species (Schwitzer 2003).

For this study, we collected data on the behaviour and activity budgets of 4 groups of blue-eyed black lemurs living in 2 different forest fragments, one mainly primary forest and the other predominantly secondary forest. The aims of our study were to provide a description of the blue-eyed black lemurs' activity pattern in their natural environment and to investigate parameters that may influence the distribution of activity over the $24 \mathrm{~h}$ cycle. Furthermore, we aimed to compare the behaviour and activity budgets of this taxon in the dry and wet seasons and when living in primary or secondary forest fragments.

\section{MATERIALS AND METHODS}

Study site. The study was conducted in the Ankarafa Forest, situated in the SW part of the UNESCO Biosphere Reserve and Protected Area on the Sahamalaza Peninsula. Sahamalaza is part of the Province Autonome de Mahajanga, NW Madagascar, and extends from $13^{\circ} 52^{\prime} \mathrm{S}$ to $14^{\circ} 27^{\prime} \mathrm{S}$ and from $47^{\circ} 38^{\prime} \mathrm{E}$ to $47^{\circ} 46^{\prime} \mathrm{E}$ (WCS/DEC 2002). The Ankarafa Forest includes primary and secondary forest fragments which harbour one of the largest populations of blueeyed black lemurs still remaining in the wild. The present study was conducted in 1 primary forest fragment and 1 secondary forest fragment.

Climate and nocturnal luminance. The climate at the study site is strongly seasonal with a cool, dry season lasting from May to September and a hot, rainy season from October to April. Mean annual precipitation is $1600 \mathrm{~mm}$, with the most rain falling in January and February. Average monthly temperatures range from $20.6^{\circ} \mathrm{C}$ (August) to $32.0^{\circ} \mathrm{C}$ (November) with a mean annual temperature of $28.0^{\circ} \mathrm{C}$.

During the study period, cloud cover and wind strength were recorded qualitatively. Categories used for assessing cloud cover were sunny (no clouds), cloudy ( $\leq 25 \%$ of the sky clouded), overcast $(>25 \%$ but $\leq 75 \%$ clouded), and heavily overcast ( $>75 \%$ clouded). Wind strength was recorded as windy, stormy, rainy, rainswept or thunderstorm.

The nocturnal illumination index $I_{\text {norm }}$ was calculated using a modified version of the method given in Curtis et al. (1999). For each night $t$ the duration of moonshine $\left(d_{\mathrm{M}}\right)$ between sunset and sunrise was multiplied with a value corresponding to the illuminated fraction of the moon $\left(f_{M}\right)$, which was modelled by a sine curve matching the given dates for new, full, waxing and waning moon. Data for moon phase and times for sunset and sunrise as well as moonrise and moonset were obtained from the US Naval Observatory Calendar (http://aa.usno.navy.mil/), using Ankarafa's geographical coordinates $\left(47^{\circ} 45^{\prime} \mathrm{E}\right.$, $14^{\circ} 22^{\prime} \mathrm{S}, \mathrm{GMT}+3 \mathrm{~h}$ ) (Donati \& Borgognini-Tarli 2006). The index was normalized to the average over the calendar year $I_{0}$. 
Sky condition (clouds) was taken into account by multiplying with a factor $C$ between 0 (heavily overcast) and 1 (clear sky) using the following equation:

$$
I_{\text {norm }}(t)=d_{\mathrm{M}} f_{\mathrm{M}} C / I_{0}
$$

where $I_{0}=\sum d_{\mathrm{M}} f_{\mathrm{M}} C$ )/\# days in calendar year. During nocturnal observations the illumination index ranged between 0.2 and 2.8 .

Observations. Four groups of Eulemur macaco flavifrons were followed for $24 \mathrm{~h} \mathrm{mo}^{-1}$ during each of 7 selected mo between July 2004 and July 2005, altogether representing $600 \mathrm{~h}$ of observations spanning the dry and the rainy season. Mean group size was 6 individuals and did not differ between forest fragments. Animals were usually followed for $6 \mathrm{~h} \mathrm{~d}^{-1}$. The observations normally started on the first day at 06:00 $\mathrm{h}$, the second day at 00:00 $\mathrm{h}$, the third day at 12:00 $\mathrm{h}$ and the 4 th day at 18:00 $\mathrm{h}$. Four observation sessions were lumped into one $24 \mathrm{~h}$ period.

Activity data of the habituated study groups were recorded by instantaneous scan sampling at $2 \mathrm{~min}$ intervals (Altmann 1974, Mann 1999, 2000). The short interval was chosen because the groups' movements were often quick and spontaneous. During daytime observations ( $240 \mathrm{~h}$ in $40 \mathrm{~d}$ ) the behaviour of each detected lemur and the spatial distribution of the group were recorded for each scan episode. Group behaviour was classified as the activity in which all or most members of the group were engaged. During nighttime observations ( $240 \mathrm{~h}$ in 34 nights) it was only possible to determine whether a majority of group members was resting or active at each sampling interval (see also Tattersall 2006).

For the collection of data on group behaviour, a lemur was considered to be part of a given group if located $\leq 50 \mathrm{~m}$ from another individual. The use of such criteria ensured that all putative group members were in visual contact with each other. The lack of distinguishing characteristics such as scars or other easily identifiable markings prevented individual identification.

Time and place of meetings between groups of lemurs, agonistic interactions, scent-marking behaviour and vocalisations were recorded ad lib (Altmann 1974, Pereira \& Kappeler 1997, Mann 2000, Scholz \& Kappeler 2004).

Data collected during observations were allocated to 2 main categories: resting (eyes half closed and/or animal curled up) and active (comprising all activities when the animal was fully alert). When the animals were not visible to the observer, data points were included in the 2 categories (active or resting) according to whether animal activity could be heard or not. Relying on acoustic data collection when the animals were not visible at night should not have created any significant sampling bias because even quiet feeding was indicated by debris falling to the ground (Curtis et al. 1999). Our nocturnal observations may have slightly underestimated the active time of the lemurs because individuals sitting still with their eyes open (classified as active during the day) are likely to have been recorded as inactive during the night. Judging from diurnal activity budgets, however, this should only have underestimated the lemurs' nocturnal activity by less than $5 \%$. In this study, we considered activity to be nocturnal if it occurred between $6 \mathrm{pm}$ and 6 am even though day length ranges from $11 \mathrm{~h} 20$ min (dry season) to 12 h 55 min (rainy season). Differences in day length are taken into account in the nocturnal illumination index, however.

Statistics. No significant difference in activity was found between the 2 study groups living in primary forest ( $G$-test: $G=0.64, \mathrm{p}>0.05$ ) or between the 2 groups in the secondary forest (G-test: $G=0.92$, p > $0.05)$. Therefore, the data within each forest condition were pooled for analysis.

The units of statistical analysis used to test for seasonal differences in activity rhythms and differences in activity between the primary and secondary forests were 38 observation sessions of $6 \mathrm{~h}$ each in the primary and 32 sessions in the secondary forest. The nonparametric $G$-test was applied to these analyses. To analyse the effects of nocturnal luminosity we used $12 \mathrm{~h}$ nights ( $\mathrm{n}=18$ ) as statistical units and applied the Friedman test and Spearman rank correlation. Data were analysed using SPSS 7.5 software (Statsoft 2001) and SSS 1.1m (Rubisoft 2002).

\section{RESULTS}

\section{Daily activity rhythms and seasonal effects}

Blue-eyed black lemurs displayed cathemeral activity over the entire study period in both types of forest, with peaks of activity occurring at dawn and dusk (Fig.1). Daily activity showed seasonal variation (Table 1, Fig. 2). During the dry season, the animals tended to decrease their total daily activity, but results were not statistically significant (G-test: $G=12.1$, p > 0.1 ). For diurnal activity, no seasonal variation was found ( $G$-test: $G=2.2$, p > 0.1), whereas nocturnal activity was significantly higher during the rainy season (G-test: $G=9.8$, p $\leq 0.05$ ).

\section{Effects of habitat structure}

The total daily activity differed between both types of forest and was significantly higher in the secondary 

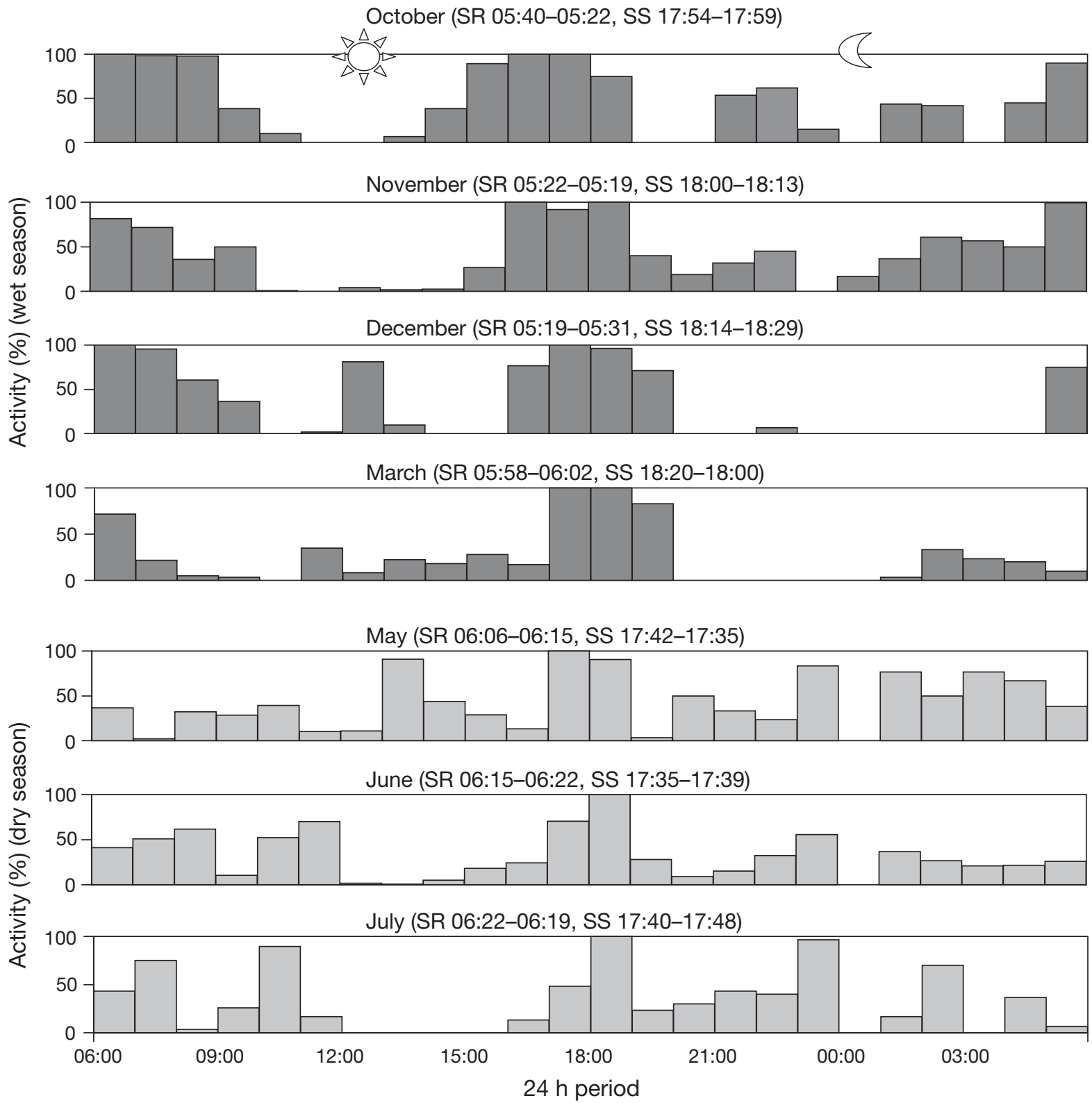

Fig. 1. Eulemur macaco flavifrons. Average monthly $24 \mathrm{~h}$ activity pattern in a primary forest fragment over the study period. Time ranges of sunrise (SR) and sunset (SS) are shown

Table 1. Eulemur macaco flavifrons. Seasonal mean proportions $( \pm$ SE) of activity (total, diurnal, nocturnal) and seasonal ratios of diurnal:nocturnal activity

\begin{tabular}{|c|c|c|c|c|}
\hline & Total & $\begin{array}{l}\text { ctivity }(\% \pm \mathrm{SE}) \\
\text { Nocturnal }\end{array}$ & Diurnal & $\begin{array}{c}\text { Diurnal: } \\
\text { nocturnal ratio }\end{array}$ \\
\hline \multicolumn{5}{|l|}{ Primary forest } \\
\hline Rainy season & $34.7 \pm 7.9$ & $28.7 \pm 19.5$ & $41.6 \pm 12.8$ & 1.5 \\
\hline Dry season & $31.7 \pm 3.5$ & $27.9 \pm 16.2$ & $35.9 \pm 12.8$ & 1.3 \\
\hline \multicolumn{5}{|c|}{ Secondary forest } \\
\hline Rainy season & $42.8 \pm 10.9$ & $50.2 \pm 14.4$ & $33.9 \pm 13.9$ & 0.7 \\
\hline Dry season & $38.4 \pm 6.2$ & $32.9 \pm 11.5$ & $37.6 \pm 16.5$ & 1.1 \\
\hline
\end{tabular}

forest throughout the year ( $G$-test: $G=$ 28.3, p $\leq$ 0.01). Nocturnal activity was significantly higher in the secondary than in the primary forest ( $G$-test: $G=$ 13.2, $\mathrm{p} \leq 0.01$ ), whereas diurnal activity did not differ significantly (G-test: $G=4.3, \mathrm{p}>0.1$ ). Differing ratios of diurnal versus nocturnal activity between forest types indicate that differences in total daily activity were due to higher nocturnal activity in the secondary forest. 


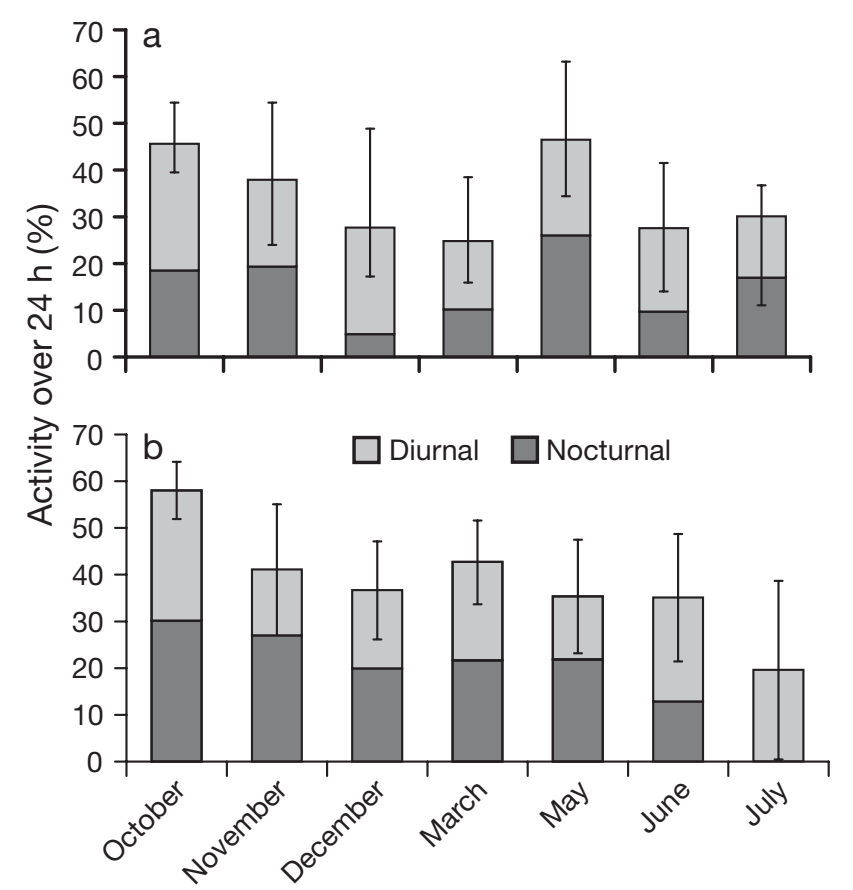

Fig. 2. Eulemur macaco flavifrons. Average $( \pm \mathrm{SE})$ monthly $24 \mathrm{~h}$ activity pattern in (a) primary and (b) secondary forest. No data on nocturnal activity for July in secondary forest: strong winds made acoustic data collection impossible

\section{Effects of nocturnal luminosity}

Cathemeral activity in Eulemur macaco flavifrons was strongly conditioned by moon luminosity in both types of forest (Fig. 3). The amount of nocturnal activity increased with the percentage of illuminated lunar disc (Friedman's $Q=3.8, \mathrm{p} \leq 0.05$; Fig. 3a). Post-hoc tests indicate significant differences in the amount of nocturnal activity between full moon $(43.37 \pm 19.97 \%)$ and new moon $(19.97 \pm 8.83 \%)$ nights, while no significant differences were found in the intermediate phases up to full moon. The amount of diurnal activity showed variations that were correlated with the moon phase of the preceding night (Fig. 3b). Comparisons of amount of diurnal activity between days succeeding full moon nights $(35.69 \pm 10.68 \%)$ and those succeeding last quarter moon nights $(28.51 \pm 8.74 \%)$ or new moon nights $(40.63 \pm 15.53 \%)$ gave significant results (Friedman's $Q=2.9, \mathrm{p} \leq 0.05$ and $Q=3.31$, p $\leq 0.05$, respectively). No significant differences in the amount of daily total activity could be established between days succeeding new, waxing, full and waning moon nights (Friedman's $Q=2.78$, p > 0.1).

Nocturnal activity also increased with the nocturnal illumination index (Fig. 4), but did not show a significant correlation (primary forest correlation coefficient $=0.54, \mathrm{p}>0.1$; secondary forest correlation coefficient $=0.291, \mathrm{p}>0.1$ ).
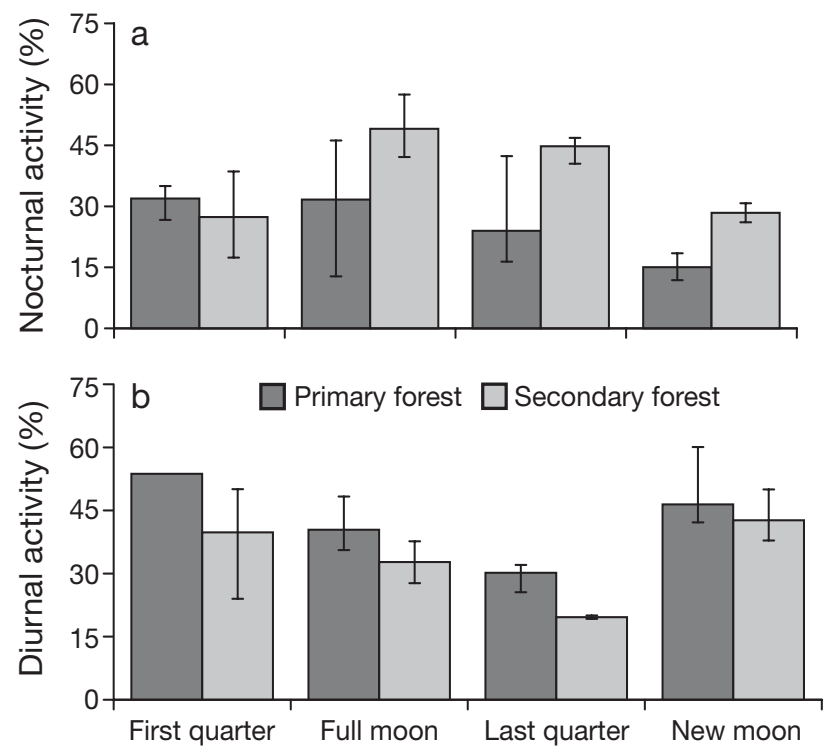

Fig. 3. Eulemur macaco flavifrons. Percent ( \pm upper and lower quartiles) of time spent active in the primary and secondary forest (a) at night during different moon phases and (b) during the day correlated with the moon phase of the preceding night

The distribution of nocturnal activity differed across the 4 main lunar phases (Fig. 5). During full moon nights $(\mathrm{n}=6)$, the lemurs were highly and almost constantly active, peaking (78\%) between 03:00 and 04:00 $h_{\text {; }}$ during new moon nights $(\mathrm{n}=4)$, activity was considerably lower (maximum hourly level $42 \%$ ); during the first quarter $(\mathrm{n}=5)$, activity was concentrated toward the end of the night; during the last quarter $(\mathrm{n}=$ $3)$, activity was also concentrated in the last hours of the night, peaking (55\%) between 03:00 and 04:00 h.

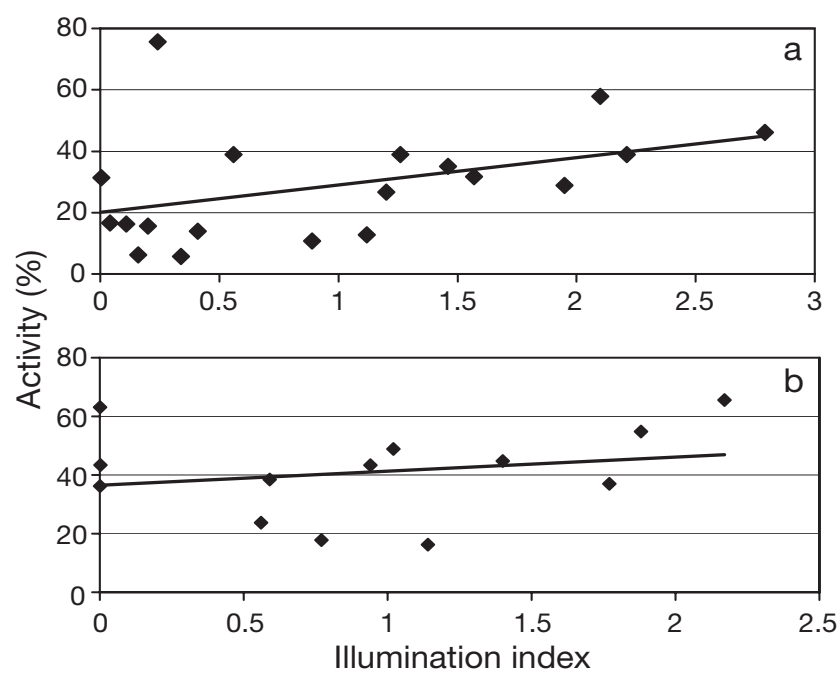

Fig. 4. Eulemur macaco flavifrons. Nocturnal activity and illumination index in (a) primary and (b) secondary forests. $\downarrow=6 \mathrm{~h}$ noctural observation sessions; 19 for primary, 13 for secondary forest 

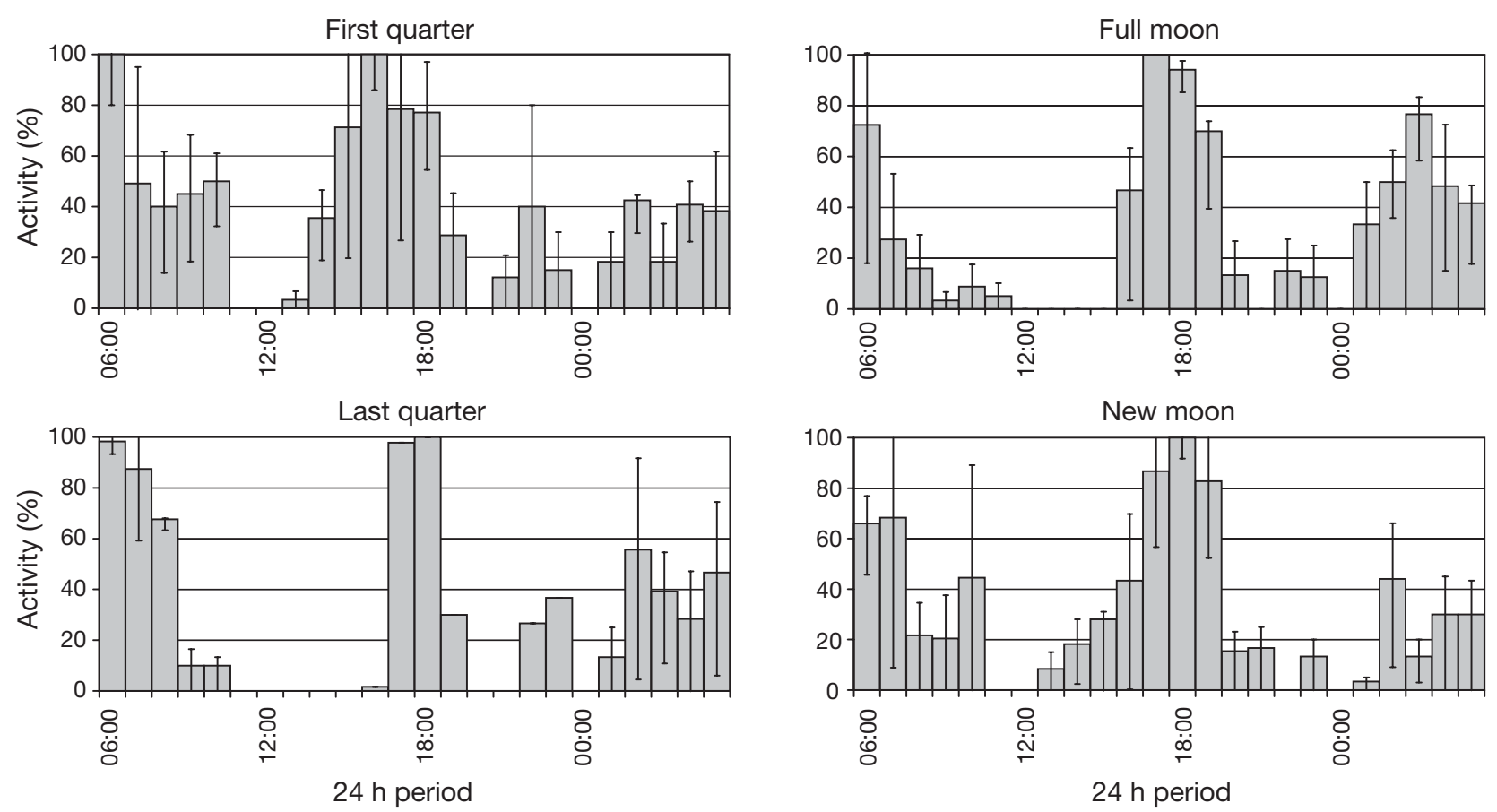

Fig. 5. Eulemur macaco flavifrons. Distribution of time spent active over the $24 \mathrm{~h}$ cycle during various moon phases. Ordinates show the amount ( $\% \pm$ upper and lower quartile) of activity per hour

\section{DISCUSSION}

\section{Total daily activity}

Cathemerality may occur in several distinct modes, and it is evident that the resulting variation in activity patterns may be controlled or at least influenced by a variety of environmental factors including temperature, rainfall, predation, food resource availability and quality, as well as varying nocturnal light levels (Tattersall 2006). Our results show that wild blue-eyed black lemurs are cathemeral all year round. The taxon has a bimodal activity pattern with peaks during morning and evening twilight. In this regard, blue-eyed black lemurs do not differ from other cathemeral lemur species, which indicates that Eulemur macaco flavifrons uses the rapid changes of light intensity during dawn and/or dusk as a time cue to entrain its circadian rhythmicity and thus to organize the majority of its activities on a daily basis.

In contrast to Eulemur mongoz (Curtis et al. 1999), E. rufus (Erkert \& Kappeler 2004) and E. collaris (Donati \& Borgognini-Tarli 2006), no pronounced seasonal shift of activity peaks from more nocturnal activity to more diurnal activity was observed. Like E. macaco macaco (Colquhoun 1998), E. m. flavifrons exhibits cathemeral activity throughout the year, a pattern also observed in all Eulemur species studied in rainforest habitat (Curtis \& Rasmussen 2002). The total daily activity of blue-eyed black lemurs tended to vary with season, in that the animals decreased their activity during the cold, dry season in both types of forest. Kappeler \& Erkert (2003) relate the decrease of daily total activity in red-fronted lemurs during the cold, dry season to the shortness of days and lower temperatures. Curtis \& Rasmussen (2006) state that western dry forest habitat offers less protection from aerial predators during the dry season, when canopy cover is greatly reduced. Furthermore, in the Sahamalaza study area, a strong wind from the SE to the NW (Varatraza) dominates the weather during June, July and August. During these months, the lemurs spent far more of the $24 \mathrm{~h}$ cycle in massive trees than during the rest of the year, huddling on branches near the trunk. This adaptive behaviour may also be responsible for the decrease of overall activity during the dry season.

\section{Effects of habitat structure}

Additionally, the habitat structure seems to affect the temporal distribution of activity. The total daily activity of blue-eyed black lemurs differed between the primary and secondary forest in that it was significantly higher in the secondary forest throughout the year. The ratio between diurnal and nocturnal activity indicates that animals are more active at night in the secondary forest than in primary forest during both 
seasons. Halle (2006) found that in fragmented landscapes the root vole Microtis oeconomus is particularly active after sunset. He explained the higher amount of nocturnal activity in a highly fragmented habitat in terms of the necessity of travelling through coverless matrices between patches. For Eulemur mongoz, low canopy density during the dry season is apparently associated with an increase in nocturnality (Curtis \& Rasmussen 2002). Diurnal movements in an open matrix are dangerous for the animals due to aerial predators such as the harrier hawk and the Madagascar serpent eagle (for an overview of predation see Colquhoun 2006). Movements might be safer during darkness when the only visually orientated predators are owls, which are not a threat to Eulemur species. In addition, secondary forest with its lower canopy density provides more nocturnal brightness and thus enhanced visibility for the lemurs.

\section{Effects of nocturnal luminosity}

Cathemeral activity in Eulemur macaco flavifrons was affected by moon luminosity in both types of forest. The amount of nocturnal activity increased with the percentage of illuminated lunar disc and nocturnal illumination index. Higher nocturnal activity with increased moonlight has also been reported for $E$. m. macaco (Colquhoun 1998) and for other lemur species in western forests, such as E. rufus (Donati et al. 2001a,b, Erkert \& Kappeler 2004) and E. mongoz (Curtis et al. 1999). Light availability seems to be an important determinant for the distribution of activity for blue-eyed black lemurs. Contrary to E. m. macaco (Colquhoun 1997, Donati et al. 2001b), E. m. flavifrons possesses a tapetum lucidum (Schwitzer et al. 2005), an adaptation for enhancing retinal sensitivity (Kirk 2006). This adaptation optimizes vision under twilight conditions, thus prolonging the daily activity period (Slatter 2001).

Although our results clearly show the influence of the illuminated fraction of the moon's disc and the duration of the moonlit part of the night, these variables alone cannot explain the lemurs' nocturnal activity pattern. During first quarter phase nights, when the moon sets around midnight, it might be expected that nocturnal activity would be concentrated in the first hours of the night rather than, as our data show, in the early morning hours. Also, if moon luminosity was indispensable for the lemurs' night activity, contrary to our observations there should have been no activity during dark (new moon) nights. It is therefore likely that additional sources of luminance contributing to sky surface brightness (i.e. airglow, zodiacal light, starlight) also influence the distribution of nocturnal activity, but a detailed analysis of these is beyond the scope of this study.

\section{Temporal behavioural plasticity in a variable environment}

The functional relevance or survival value of cathemerality is difficult to determine. According to several authors, increased nocturnal activity during the dry, cool season might be regarded as a mechanism for increasing body temperature through movement (Overdorff \& Rasmussen 1995, Donati et al. 1999, Kappeler \& Erkert 2003). Our study does not support this hypothesis, because in Eulemur macaco flavifrons nocturnal activity differed between seasons only in the secondary forest and was higher during the warm, wet months of the year.

Engqvist \& Richard (1991) propose that cathemerality is a response to dietary seasonality. By increasing their activity in times of food scarcity, the animals would be better able to cope with a fibrous diet (Mutschler 2004). Neither Eulemur macaco flavifrons nor E. m. macaco increased activity during periods of lower food availability (cold, dry season). On the contrary, both taxa even decreased their activity during times of food scarcity (see also Colquhoun 1998).

Colquhoun (2006) proposes a co-evolutionary relationship between the activity patterns of the fossa Cryptoprocta ferox, the main terrestrial predator of Eulemur species, and those of cathemeral lemurs, concluding that predation may have been one of the main driving forces of the evolution of cathemerality in lemurs. Hill (2006) comes to a similar conclusion. During our study of Eulemur macaco flavifrons, we were not able to observe a predation event, although the lemurs frequently reacted to the presence of potential avian predators by emitting alarm calls. Future longterm studies may show to what extent the cathemerality of blue-eyed black lemurs may be beneficial for avoiding predation by terrestrial or avian predators.

A number of ecological influences may have played a role in the evolution of a cathemeral activity pattern in the blue-eyed black lemur. The main activity peaks for this species occur in the early morning and late afternoon when temperatures are lower than the rest of the day (see also Andrews \& Birkinshaw 1998). Moreover, afternoon activity coincides with increased concentrations of soluble carbohydrates in leaves (Wright 1999), one of the food resources of Eulemur macaco flavifrons. An advantage of nocturnal activity would be the absence of diurnal aerial predators. On the other hand, heavy rainfall seems to promote lower activity levels, as does the lack of sufficient light intensity during the night. In view of our results, the cathe- 
meral behaviour of E. $m$. flavifrons may best be explained as the result of flexible responses to a framework of varying environmental factors, each of which may enhance or inhibit activity within the lemurs' range of adaptability. Temporal behavioural plasticity may be an adaptation to an erratic and severe climate with frequent droughts and cyclones and unpredictable resource availability (Wright 1999).

Acknowledgements. We thank the DGEF and the Malagasy National Parks Authority ANGAP for granting a research permit, as well as C. Rabarivola from the University of Mahajanga, H. Zahner from the University of Giessen and G. Nogge from Cologne Zoo (Zoologischer Garten Köln) for their assistance. We also thank I. Oravaka for helping with climate data analysis, as well as our field assistants Yvess C. Jaomamory and Tombomisy Jean-Ede, without whose help the nocturnal observations would not have been possible. Thank you also to J. Ganzhorn, I. Colquhoun, F. Ruperti, D. Curtis and P. Wright, who all provided very helpful comments on the manuscript. This study was supported by AEECL, the Margot Marsh Biodiversity Foundation and the Conservation International Primate Action Fund. Equipment was sponsored by Thrane \& Thrane in Lyngby, Denmark and Bushnell in Cologne, Germany.

\section{LITERATURE CITED}

Altmann J (1974) Observational study of behaviour: sampling methods. Behaviour 49:227-265

Andrews JR, Birkinshaw CR (1998) A comparison between the daytime and nighttime diet, activity and feeding height of the black lemur, Eulemur macaco (Primates: Lemuridae), in Lokobe Forest, Madagascar. Folia Primatol 69(Suppl 1):175-182

Colquhoun IC (1997) A predictive socioecological study of the black lemur (Eulemur macaco macaco) in northwestern Madagascar. Diss Abstr Int A58:1354

Colquhoun IC (1998) Cathemeral behavior of Eulemur macaco macaco at Ambato Massif, Madagascar. Folia Primatol 69(Suppl 1):22-34

Colquhoun IC (2006) Predation and cathemerality: comparing the impact of predators on the activity patterns of lemurids and ceboids. Folia Primatol 77:143-165

Curtis DJ, Rasmussen MA (2002) Cathemerality in lemurs. Evol Anthropol 11(Suppl 1):83-86

Curtis DJ, Rasmussen MA (2006) The evolution of cathemerality in primates and other mammals: a comparative and chronoecological approach. Folia Primatol 77:178-193

Curtis DJ, Zaramody A (1998) Group size, home range use, and seasonal variation in the ecology of Eulemur mongoz. Int J Primatol 19:811-835

Curtis DJ, Zaramody A, Martin RD (1999) Cathemerality in the mongoose lemur, Eulemur mongoz. Am J Primatol 47: $279-298$

Curtis DJ, Donati G, Rasmussen MA (2006) Cathemerality: preface. Folia Primatol 77:5-6

Dahl JF, Hemingway CA (1988) An unusual activity pattern for the mantled howler monkey of Belize. Am J Phys Anthropol 75:201

Donati G, Borgognini-Tarli SM (2006) Influence of abiotic factors on cathemeral activity: the case of Eulemur fulvus collaris in the littoral forest of Madagascar. Folia Primatol 77: $104-122$
Donati G, Lunardini A, Kappeler PM (1999) Cathemeral activity of red-fronted brown lemurs (Eulemur fulvus rufus) in the Kirindy Forest/CFPF. In: Rakotosamimanana B, Rasamimanana H, Ganzhorn JU, Goodman SM (eds) New directions in lemur studies. Kluwer Academic Plenum, New York, p 119-137

Donati G, Lunardini A, Kappeler PM, Borgognini-Tarli SM (2001a) Nocturnal activity in the cathemeral red-fronted brown lemur (Eulemur fulvus rufus): variations during a lunar eclipse. Folia Primatol 72:147

Donati G, Lunardini A, Kappeler PM, Borgognini-Tarli SM (2001b) Nocturnal activity in the cathemeral red-fronted lemur (Eulemur fulvus rufus), with observations during a lunar eclipse. Am J Primatol 53:69-78

Engqvist A, Richard A (1991) Diet as a possible determinant of cathemeral activity patterns in primates. Folia Primatol 57:169-172

Erkert HG, Cramer B (2006) Chronobiological background to cathemerality: circadian rhythms in Eulemur fulvus albifrons (Prosimii) and Aotus azarai boliviensis (Anthropoidea). Folia Primatol 77:87-103

Erkert HG, Kappeler PM (2004) Arrived in the light: diel and seasonal activity patterns in wild Verreaux's sifakas (Propithecus V. verreauxi; Primates: Indriidae). Behav Ecol Sociobiol 57:174-186

Fernandez-Duque E (2003) Influences of moonlight, ambient temperature, and food availability on the diurnal and nocturnal activity of owl monkeys (Aotus azarai). Behav Ecol Sociobiol 54:431-440

Fernandez-Duque E, Erkert HG (2006) Cathemerality and lunar periodicity of activity rhythms in owl monkeys of the Argentinean Chaco. Folia Primatol 77:123-138

Ganzhorn $\mathrm{J}$ and members of the Primate Specialist Group (2000) Eulemur macaco ssp. flavifrons. In: IUCN 2006. 2006 IUCN Red List of Threatened Species. Available at: www.iucnredlist.org

Grassi C (2001) Seasonal variability in the activity budget of Hapalemur griseus griseus. Am J Primatol 54(Suppl 1):43

Halle S (2006) Polyphasic activity patterns in small mammals. Folia Primatol 77:15-26

Hill RA (2006) Why be diurnal? Or, why not be cathemeral? Folia Primatol 77:72-86

Kappeler PM, Erkert HG (2003) On the move around the clock: correlates and determinants of cathemeral activity in wild red-fronted lemurs (Eulemur fulvus rufus). Behav Ecol Sociobiol 54:359-369

Kinzey WG (1997) Synopsis of New World primates: Aotus. In: Kinzey WG (ed) New World primates: ecology, evolution, and behavior. Aldine de Gruyter, New York, p 186-191

Kirk CE (2006) Eye morphology in cathermeral lemurids and other mammals. Folia Primatol 77:27-49

Koenders L, Rumpler Y, Ratsirarson J, Peyrieras A (1985) Lemur macaco flavifrons (Gray, 1867): a rediscovered subspecies of primates. Folia Primatol 44:210-215

Mann J (1999) Behavioral sampling methods for cetaceans: a review and critique. Mar Mamm Sci 15:102-122

Mann J (2000) Unravelling the dynamics of social life: longterm studies and observational methods. In: Mann J, Connor RC, Tyack PL, Whitehead H (eds) Cetacean societies: field studies of dolphins and whales. University of Chicago Press, Chicago, IL, p 45-64

Meier B, Lonina A, Hahn T (1996) Summer 1995 expedition report on the creation of a new national park in Madagascar. Z Koeln Zoo 39:61-72

Mutschler T (2002) Alaotran gentle lemur: some aspects of its behavioral ecology. Evol Anthropol 11(Suppl 1):101-104

Mutschler T (2004) Food availability, diet and cathemerality. 
Folia Primatol 75(Suppl 1):68

Mutschler T, Feistner ATC, Nievergelt CM (1998) Preliminary field data on group size, diet and activity in the Alaotran gentle lemur Hapalemur griseus alaotrensis. Folia Primatol 69:325-330

Overdorff DJ, Rasmussen MA (1995) Determinants of nighttime activity in 'diurnal' lemurid primates. In: Alterman L, Doyle GA, Izard MK (eds) Creatures of the dark: the nocturnal prosimians. Plenum Press, New York, p 61-74

Pereira ME, Kappeler PM (1997) Divergent systems of agonistic behaviour in lemurid primates. Behaviour 134:225-274

Rasmussen MA (1998a) Ecological influences on cathemeral activity in the mongoose lemur (Eulemur mongoz) at Ampijoroa, northwest Madagascar. Am J Primatol 45:202

Rasmussen MA (1998b) Variability in the cathemeral activity cycle of two lemurid primates at Ampijoroa, northwest Madagascar. Am J Phys Anthropol Suppl 26:183

Rasmussen MA (1999) Ecological influences on activity cycle in two cathemeral primates, Eulemur mongoz (mongoose lemur) and Eulemur fulvus fulvus (common brown lemur). $\mathrm{PhD}$ thesis, Duke University, Durham, NC

Scholz F, Kappeler PM (2004) Effects of seasonal water scarcity on the ranging behavior of Eulemur fulvus rufus. Int J Primatol 25:599-613

Schwitzer C (2003) Energy intake and obesity in captive lemurs (Primates, Lemuridae). PhD thesis, Universität zu Köln

Schwitzer N, Kaumanns W, Zahner H, Schwitzer C (2005) Cathemerality in blue-eyed black lemurs (Eulemur macaco flavifrons) on the Sahamalaza peninsula, north-

Editorial responsibility: Alan Dixson, Welllington, New Zealand west Madagascar. Primate Rep 72:88-89

Slatter D (2001) Fundamentals of veterinary ophthalmology, 3rd edn. WB Saunders, Philadelphia, PA

Tan CL (2000) Patterns of resource use in three sympatric Hapalemur species in Ranomafana National Park, Madagascar. Am J Phys Anthropol Suppl 30:299

Tarnaud L (2006) Cathemerality in the mayotte brown lemur (Eulemur fulvus): seasonality and food quality. Folia Primatol 77:166-177

Tattersall I (1979) Patterns of activity in the mayotte lemur, Lemur fulvus mayottensis. J Mamm 60:314-323

Tattersall I (1987) Cathemeral activity in primates: a definition. Folia Primatol 49:200-202

Tattersall I (2006) The concept of cathemerality: history and definition. Folia Primatol 77:7-14

Vasey N (2000) Niche separation in Varecia variegata rubra and Eulemur fulvus albifrons: I. interspecific patterns. Am J Phys Anthropol 112:411-431

WCS/DEC (Wildlife Conservation Society/Development Environment Consult) (2002) Etude de faisabilité de la création d'APMC et plan de développement pour le site de la RBM Sahamalaza - Nosy Radama. WCS/DES, Antananarivo

Wright PC (1994) The behavior and ecology of the owl monkey. In: Baer JF, Weller RE, Kakoma I (eds) Aotus: the owl monkey. Academic Press, San Diego, CA, p 97-112

Wright PC (1999) Lemur traits and Madagascar ecology: coping with an island environment. Yearb Phys Anthropol 42: $31-72$

Submitted: January 26, 2007; Accepted: July 19, 2007 Proofs received from author(s): September 7, 2007 